http://dx.doi.org/10.18232/alhe.1069

Artículos

\title{
Efectos de las reformas del Consenso de Washington sobre la estructura industrial: Los casos de México e India
}

\section{Effects of the Washington Consensus reforms on the industrial structure: The cases of Mexico and India}

\author{
Raúl Vázquez-López ${ }^{1,}$ * (DD 0000-0001-8098-1336
}

${ }^{1}$ Universidad Nacional Autónoma de México, Ciudad de México, México.

*Correspondencia: rvazquez@unam.mx

Resumen. Este artículo tiene por objetivo comparar las transformaciones estructurales ocurridas en el sector industrial de India y México, después de reformas económicas similares, inspiradas en el Consenso de Washington. La evolución del indicador de productividad laboral, calculado para 90 categorías, en el caso de México, en el periodo 1994-2007, y de 123 categorías para la India, de 1998 a 2007, corrobora un aumento de las disparidades entre las industrias, así como una concentración de la modernización en un número reducido de actividades. Los resultados muestran un proceso relativo de reestructuración y modernización productiva en la India, con un cierto rezago temporal, y una evolución más cuestionable en México, debido a una excesiva especialización dependiente de la dinámica de las empresas multinacionales. Por último, una metodología diferencial estructural confirma la hipótesis, según la cual, en ninguno de los dos casos, existe un cambio estructural impulsor de los niveles de eficiencia agregados.

Palabras clave: Consenso de Washington; cambio estructural; industria.

Abstract. This article aims to compare the structural transformations that took place in the industrial sector of Mexico and India, after similar economic reforms, inspired in the Washington Consensus. The evolution of the labor productivity indicator, calculated for 90 categories from 1994 to 2007 in Mexico's case,

CÓMO CITAR: Vázquez-López, R. (2020). Efectos de las reformas del Consenso de Washington sobre la estructura industrial: Los casos de México e India. América Latina en la Historia Económica, 27(3), e1069. DOI: 10.18232/alhe.1069

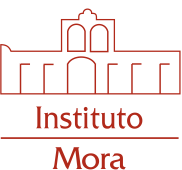


and from 1998 to 2007 with 123 categories for India, corroborates widening disparities among the various industries as well as a concentration of modernization in a reduced number of activities. The results show a relative process of restructuring and productive modernization in India, with a certain time lag, and a more questionable evolution in Mexico, due to an excessive specialization dependent on multinational firms' dynamics. Finally, a shift-share methodology confirms the hypothesis that in neither case there was a structural change bolstering aggregated efficiency levels.

Key words: Washington Consensus; structural change; Industry.

JEL: L16; N10; O14; O19; O25.

Recibido: 27 de febrero de 2019

Aceptado: 26 de junio de 2019

Publicado: 26 de julio de 2020.

Organismo patrocinador: Investigación realizada tras estancia en la Universidad Jawaharlal Nehru de la India con el apoyo del Programa de Apoyos para la Superación del Personal Académico de la Universidad Nacional Autónoma de México.

\section{INTRODUCCIÓN}

A pesar de los múltiples contrastes geográficos, históricos, sociales, y culturales, existentes entre la India y México, la conducción estatal de la economía desde los años cincuenta del siglo pasado, hasta la crisis de 2008, tiene muchos rasgos comunes, lo que hace especialmente relevante una comparación entre estos dos países, en términos de la aplicación de medidas de política pública. En ambos casos, las autoridades inspiradas, tras la segunda guerra mundial en el caso de México, y tras la consecución de la independencia en la India, por un nacionalismo desarrollista que enarbola la necesidad de una transformación estructural, basada en el fortalecimiento de la industria, establecen una estrategia de industrialización por sustitución de importaciones (ISI). Tras el agotamiento de este modelo, a finales de los años setenta, e inicios de los ochenta, se implementa a su vez en los dos países, una reforma económica siguiendo los lineamientos del Consenso de Washington (1989).

En América Latina, los años ochenta se conocen como la década perdida debido entre otros, al estancamiento económico y al elevado endeudamiento de los gobiernos de la región, con motivo del incremento de los precios del petróleo y de los tipos de interés internacionales. En este contexto, varios países latinoamericanos como Brasil, México, y Argentina, se ven forzados a suspender el servicio de la deuda externa, y a renegociar apoyos financieros con los principales organismos internacionales. En noviembre de 1989, un grupo de reconocidos economistas y representantes de estos organismos, llegan a un consenso acerca de los diez instrumentos de política económica que los Estados de la región deben implementar para salir de la crisis y recibir los apoyos requeridos (disciplina fiscal, reordenación de las prioridades del gasto público, reforma fiscal, liberalización financiera, tipo de cambio competitivo, liberalización del comercio, liberalización de la inversión extranjera directa, privatizaciones, desregulación y derechos de propiedad). En esencia, este programa de ajuste, el Consenso de Washington, es diseñado para América Latina, y después se hace aplicable a cualquier región del mundo (Martínez y Soto, 2012).

$\mathrm{Al}$ respecto, el estudio comparativo de las medidas implementadas, siguiendo los lineamientos del Consenso de Washington, y de sus primeros resultados, en los casos de India y México, a un alto

nivel de desagregación sectorial, permite señalar el cambio radical de orientación producido en las 
estrategias de desarrollo establecidas en dos regiones distintas, dando luz sobre los rasgos comunes de las transformaciones estructurales ocurridas en esos años, pero también sobre sus diferencias, y sobre los principales determinantes de las mismas. Los contrastes en el ritmo de implementación de las medidas, sus especificidades, y en especial, el punto de partida y el tipo de inserción global de las distintas actividades en estos dos países, permiten comprender las diferencias en los resultados obtenidos, y en última instancia, realizar propuestas alternativas de política pública y gobierno. Es de subrayar entonces que las conclusiones del análisis, si bien pueden ser el punto de inicio para la revisión de otros casos de interés, dependen exclusivamente de la selección de los países estudiados en términos de la evaluación de las políticas aplicadas. De hecho, algunos autores apuntan que las fallas de las políticas del Consenso de Washington, se originan en la falta de reconocimiento en su aplicación, de las diferencias en las dotaciones factoriales y ventajas comparativas existentes entre los países donde fueron implementadas (Lin, 2015).

Desde una perspectiva teórica estructural, la valoración de los efectos de las reformas económicas, inspiradas en el Consenso de Washington, sobre el desarrollo industrial de un determinado país, depende de la evolución de los grados de concentración, heterogeneidad, y modernización del conjunto de las actividades. Los cambios en el tiempo de la productividad laboral, y de sus determinantes, en cada industria, deben ser entendidos como una referencia de primer orden para el estudio de las transformaciones estructurales ocurridas. Un desarrollo industrial equilibrado y sostenible requiere un proceso de homogeneización en las prácticas y formas de organización y funcionamiento de los segmentos productivos (Furtado, 1961; Pinto, 1965), con especial énfasis en el aprovechamiento de los recursos disponibles considerados escasos, mediante la movilidad de los factores en dirección de los usos más eficientes (Prebisch, 1950). Siguiendo la misma lógica, otro referente teórico es entonces la diversificación del tejido de fabricación, ya que permite "escalar" en el contenido de conocimiento implícito en los bienes fabricados, y generar una competitividad sustentada en ventajas comparativas dinámicas con mayores ingresos (Cimoli, Correa y Primi, 2003).

Es desde este enfoque teórico que el presente trabajo se plantea entonces las siguientes interrogantes: ¿Cuáles fueron los efectos de las reformas económicas establecidas a partir de los años ochenta sobre los grados de concentración, heterogeneidad y modernización estructurales en el sector industrial de México e India? ¿Existió un cambio estructural significativo? ¿Qué aspectos explican las diferencias en los resultados obtenidos?

Tras realizar un breve recuento de las medidas implementadas siguiendo los lineamientos del Consenso de Washington, particularmente en lo referente a la industria de cada uno de los países, en un segundo apartado, este artículo sintetiza los resultados previamente obtenidos por otros estudios relativos a la evolución de la productividad laboral y total de los factores en India y México. En una tercera parte, la construcción de una base de datos y el cálculo de la productividad laboral al nivel más desagregado posible (cuatro dígitos de la International Standard Industrial Classification revisión 3 [ISIC rev. 3]) permite comparar las transformaciones estructurales ocurridas en el sector, en ambos casos, a partir del seguimiento en el tiempo del indicador. El cuarto segmento aborda entonces la cuestión del cambio estructural, a través del estudio de los determinantes de las variaciones en la productividad laboral, utilizando una técnica genérica de tipo diferencial-estructural. Finalmente, se señalan las principales conclusiones, cuya relevancia histórica es innegable, puesto que los cambios documentados en este artículo están al origen de las dinámicas actuales de funcionamiento del aparato productivo de ambos países, y en particular, de sus limitaciones estructurales.

Reforma económica y política industrial 
A partir de una crítica a la teoría de la especialización, basada en la inestabilidad internacional de los precios de los productos primarios, el deterioro de los términos del intercambio, y los déficits en la balanza de pagos, en países latinoamericanos, la ISI en México, se centró en modificar las ventajas comparativas en favor de las manufacturas, y de las industrias incipientes, en detrimento de la agricultura (Guillén, 2013). Durante al menos dos décadas, la aplicación de políticas fiscales y comerciales, dirigidas a estimular el desarrollo de la industria, y protegerla de la competencia externa, permitió el crecimiento de un sector diversificado y maduro que apuntaló la ampliación del mercado interno y el incremento de los niveles de bienestar de la población (Cárdenas, 2003). Con el tiempo, las contradicciones del proceso se agravaron gradualmente, la sustitución de importaciones, inicialmente exitosa en lo referente a los bienes de consumo, se hizo cada vez más difícil, en el caso de los bienes de capital con alto grado de intensidad tecnológica.

Las empresas establecidas en el país, tanto las mexicanas como las transnacionales, carecían de incentivos para mejorar sus procesos, innovar o mejorar la calidad de sus productos, dado que el control ejercido sobre el mercado local era por demás redituable. El proteccionismo además de propiciar corrupción, clientelismo, y contrabando, generó entonces industrias ineficientes en situación de oligopolio, en mercados protegidos con precios elevados, que afectaban a los consumidores (Anima y Guerrero, 2001). Aunque estos problemas son flagrantes a mediados de los años setenta, el descubrimiento de yacimientos petroleros perpetua la vida de dicha estrategia, hasta la crisis de la deuda en 1982, cuando las autoridades bajo la presión del Fondo Monetario Internacional (FMI) deciden establecer a marchas forzadas un nuevo modelo, siguiendo los lineamientos del Consenso de Washington, cuyas fechas significativas son el ingreso del país al GATT en 1986, y la firma del Tratado de Libre Comercio para América del Norte (TLCAN) en 1994 (Guillén, 2013).

En este contexto, el nuevo proyecto de modernización, reconversión industrial, y cambio estructural, corresponde a la instrumentación de un patrón de acumulación secundario-exportador, el cual consiste en la sustitución de exportaciones primarias y petroleras, por la exportación de productos manufacturados, tales como los textiles y electrónicos entre otros. Esta política tiene como base el aprovechamiento de las ventajas competitivas estáticas de la economía nacional, es decir el bajo costo de la mano de obra y la cercanía con los Estados Unidos (Valenzuela, 1994). En lo referente al sector industrial, una política genérica horizontal, centrada en la promoción de las exportaciones, especialmente de las maquiladoras, sustituye a una serie de instrumentos de fomento sectorial y de programas estratégicos diseñados para industrias específicas. Se implementan programas como Pitex 17 Inmex ${ }^{2}$, y Drawback ${ }^{3}$ consistentes en exentar del pago de impuestos (general de importación, al valor agregado, así como en su caso, de cuotas compensatorias) a las importaciones temporales de bienes e insumos utilizados en los procesos industriales de elaboración, transformación, o reparación, de mercancías de exportación (Hernández, 2000).

A manera de ejemplo, en el nuevo marco regulatorio del Decreto Automotriz, principal industria del sector, se eliminan: A partir de 1998, el límite máximo permitido de participación extranjera en las empresas (que era de $49 \%$ ); en el año 2004, el requisito de un contenido nacional mínimo en lo bienes fabricados que se había ubicado hasta antes de 1998 en $60 \%$; y gradualmente el requisito de la balanza comercial (Hernández, 2000). En términos generales, la modificación de

\footnotetext{
${ }^{1}$ Programa de Importación Temporal para producir artículos de Exportación (PITEX).

${ }^{2}$ Industrias Manufacturera, Maquiladora y de servicios de Exportación (INMEX).

${ }^{3}$ Devolución de Impuestos de Importación a los Exportadores (Drawback).
} 
la composición de la producción manufacturera, en función de las necesidades productivas globales, se da mediante una política de especialización de las empresas exportadoras en actividades de ensamblaje, caracterizadas por un reducido contenido de conocimientos tecnológicos domésticos, y vía el desplazamiento de la producción local por las importaciones. En cuanto a los demás aspectos, al analizar la competitividad de la economía mexicana, desde una perspectiva que se pretende sistémica, Villarreal y Ramos (2001, p.777) señalan el carácter "pasivo" de la política sectorial y citan una conocida frase: "... la mejor política industrial es la que no existe".

En cuanto a la India, hasta los años ochenta, el modelo de desarrollo económico se apoyó en el impulso focalizado a industrias pesadas de gran tamaño bajo control estatal, y siguiendo la lógica de una Industrialización por Sustitución de Importaciones (ISI), apuntalada por rígidos controles de precios y restricciones a la iniciativa privada (Srinivasan, 1996). Siguiendo estas grandes líneas de acción, la estrategia experimentó diversas fases reveladoras de una interpretación cambiante de las necesidades del desarrollo productivo por parte de las autoridades nacionales. Bhagavan (1995) menciona por ejemplo cuatro periodos diferenciados, en el primero (1950-1965) y más significativo, el control estatal total de la fabricación de maquinaria e insumos intermedios claves se combina con la presencia de compañías privadas nacionales y extranjeras, limitada a la producción de bienes de consumo y bienes intermedios no considerados estratégicos por el Estado. En un segundo lapso (1966-1984), la renuncia en la práctica a la pretensión de cerrar las brechas tecnológicas, con respecto a las naciones líderes de occidente, marca el inicio de la declinación de la participación del sector público en la industria.

Por su parte, el tercer periodo (1985-1991) es señalado por el retiro del Estado de la conducción de la economía, y la entrada del sector privado, en aéreas reservadas hasta entonces al sector público, el número de nuevos acuerdos de colaboración tecnológica con empresas foráneas alcanza entre 1985 y 1990, los 5 203, cifra superior en $80 \%$ a la registrada entre 1980 y 1984 (2 916 casos) (Government of India. Department of Scientific and Industrial Research, 1992, 1992). En estos años, se fortalece la estrategia de liberalización de las importaciones para la modernización industrial que culmina con la implementación en julio de 1991 del Programa de estabilización y ajuste estructural (SAP) (última fase). Al respecto, diversos autores (Bhagwati y Desai, 1970) señalan que el desarrollo hacia adentro tuvo por consecuencia una considerable ineficiencia en el sector industrial, evidenciado entre otros aspectos, por el bajo crecimiento de la productividad. Ahluwalia (1991) estima tasas de crecimiento promedio anuales, del trabajo y total de los factores (TFP), de alrededor de $2 \%$ y $0 \%$, respectivamente, entre $1959-1960$ y 1979-1980.

Lo anterior conlleva una serie de reformas, basadas en la desregulación económica y la apertura comercial, que se agudizan a partir de 1991, como resultado de la severa crisis económica y en especial fiscal, experimentada por el país en ese año. Las autoridades reestructuran el mercado doméstico de capitales, a través de la liberalización de las tasas de interés, a la vez que levantan las restricciones a la inversión, por parte de las grandes empresas bajo control extranjero, hasta entonces contenidas en el MRTP Act (Monopoly Restrictive Trade Policy Act). Se reducen asimismo los controles administrativos y obstáculos al comercio exterior, por lo que, en un contexto de mayor competencia, el éxito de las reformas recae en la posibilidad de aumentar los niveles de productividad (Bhaumik, Gangopadhyay y Krishnan, 2009). En suma, las principales medidas se concentraron en: Reducir o eliminar los impuestos, licencias, y cuotas al comercio exterior; disminuir las barreras a la entrada de la inversión extranjera; permitir el acceso de la iniciativa privada a industrias antes reservadas al Estado; reducir y simplificar la estructura impositiva; y flexibilizar y aumentar la supervisión y regulación del sistema bancario (Unel, 2003). 
Un aspecto relevante a considerar está relacionado con los tiempos de las reformas económicas. A diferencia del caso mexicano, en el que las medidas fueron implementadas a un ritmo acelerado, y con algunas excepciones aplicadas todas en su conjunto, en la India, el acceso al capital extranjero fue un proceso gradual que inició junto con la liberalización comercial de los bienes de capital a principios de los años noventa. De hecho, la eliminación de las restricciones a la importación de la mayoría de los bienes de consumo, se da hasta inicios del nuevo milenio, mientras en 2004, se decreta la elevación de los límites máximos a la IED en los sectores bancarios (74\%), de exploración de petróleo (100\%), de mercadotecnia de productos petroleros $(100 \%)$, y de productos petroleros (100\%), en 2005 , se da el aumento de $49 \%$ a $74 \%$, en diversos servicios de telecomunicaciones (Bhat, 2013).

En lo específico a la nueva política industrial y tecnológica del país, establecida como parte del Programa SAP, destacan la abolición en la mayoría de las ramas, con excepción de las consideradas sensibles por razones estratégicas, sociales, ambientales, o de seguridad, del sistema de licenciamiento industrial que limitaba los montos de fabricación. Se establece el permiso automático, aunque con ciertas restricciones, a las importaciones de bienes de capital asociadas a proyectos de inversión foráneos. Se autoriza la propiedad extranjera de hasta $51 \%$ de cualquier firma en las 34 industrias calificadas de alta prioridad, en las que se aprueban todos los acuerdos tecnológicos con proveedores extranjeros, y se eliminan en lo general, los permisos para contratar técnicos del exterior. Se abren a la iniciativa privada las ocho industrias consideradas estratégicas, hasta entonces reservadas a las empresas públicas, cuyo funcionamiento es en adelante sometido a revisiones críticas y penalizaciones, con criterios específicos de eficiencia, desarrollo tecnológico, y pertinencia económica y social. Por último, es de señalar la eliminación de las provisiones centrales del MRTP Act., con el fin de permitir una mayor concentración empresarial, a través de fusiones y adquisiciones (Bhagavan, 1995).

\section{Revisión de la literatura: Estudios de la PROductividad en India y MÉXico}

En términos generales, la mayoría de los estudios existentes para la India, relativos a la evolución de la productividad, en los primeros años tras las reformas económicas emprendidas, indican un incremento de las tasas del indicador, tanto para el sector en su conjunto, como para sus principales industrias (Driffield y Kambhampati, 2003; Unel, 2003). A manera de ejemplo, a partir de la estimación de una función de producción estándar, bajo el supuesto de rendimientos a escala constantes de los factores, Unel (2003) estima un aumento de la productividad laboral y total de los factores, de $24 \%$ y 46 \% respectivamente, al comparar los periodos 1959-79 y 1979/80-1997/98. De igual forma, la literatura documenta una disminución del ritmo de crecimiento de la eficiencia, a fines de los noventa, tras la implementación del grueso de las reformas (Trivedi, Prakash y Sinate, 2000; Goldar y Kumari, 2003), dando pie a diversas interpretaciones entre las que se encuentra, el deterioro en el grado de utilización de la capacidad productiva, debido a mayores inversiones e importaciones, sin el correspondiente aumento de la demanda (Uchikawa, 2001; Goldar y Kumari, 2003).

Entre los trabajos sobre los efectos de las reformas en la productividad industrial, a nivel de rama o industria, para el periodo de estudio, es de destacar el trabajo de Pattnayak y Thangavelu (2001), quienes estudian la evolución de la productividad total de los factores (TFP) en la manufactura, a nivel de 70 industrias, para el lapso 1980-1997, y realizan un primer acercamiento al análisis del cambio estructural en el sector a través de una descomposición de las variaciones de 
la TFP. Uno de los principales hallazgos es la evidencia de una elevada, y cada vez mayor, concentración de las prácticas eficientes en un número reducido de actividades. Al distinguir entre dos periodos, 1980-1985 y 1991-1997, resulta que, en el primer caso, 27 industrias, $35 \%$ de la producción sectorial, explican la totalidad del incremento acumulado de la TFP manufacturera $(3.40 \%)$, mientras en el segundo, 12 industrias, $14 \%$ de la producción sectorial, significan el $100 \%$ del aumento de la TFP (2.94 \%). A grandes rasgos, se observa que, tras las reformas y la apertura comercial, una parte creciente de la estructura, con tasas negativas de cambio en el indicador, fue incapaz de realizar las inversiones necesarias para mantenerse competitiva, por lo que la cantidad de industrias eficientes se redujo (mientras en 1980-85, 78.11\% de la producción manufacturera registró aumentos en la TFP, en 1991-1997, esta cifra bajó a $57 \%$ ).

Por su parte, las estimaciones de Kim y Saravanakumar (2012), para un periodo más reciente (2001-2006), muestran un crecimiento promedio mayor de la productividad total de los factores en las industrias metálicas y de transporte, e incrementos inferiores en las no-metálicas y de textiles. El trabajo distingue un primer grupo de ramas, en las que el indicador tuvo un mejor desempeño, compuesto por las industrias de maquinaria, metal, transporte, y químicas, seguidas por un segundo grupo constituido por las actividades relacionadas con los alimentos y los textiles, siendo la industria no-metálica, la única con tasas negativas de crecimiento de la TFP. En suma, sus resultados apuntan en dirección de la ampliación de las brechas existentes, en términos tecnológicos, entre sectores atrasados y modernos, lo que confirmaría, por un lado, un importante rezago en el tiempo del impacto de la inversión sobre la eficiencia productiva, y por otro, una tendencia creciente de la heterogeneidad y de la concentración estructural en el sector.

Finalmente, Virmani y Hashim (2011) postulan un comportamiento en forma de S del indicador factorial tras las reformas, como consecuencia de un rápido impacto positivd de la utilización de nueva maquinaria, así como de la rigidez de las leyes laborales, que incentivan el uso de tecnologías más intensivas en capital y restringen la contratación de nuevos trabajadores. Sus cálculos arrojan para nuestro periodo de análisis (1998-1999 y 2007-2008), un incremento de $6.7 \%$ anual en la productividad laboral del sector, con tasas mayores para el lapso más reciente (2002-2003 y 2007-2008) en las ramas asociadas a la fabricación de bienes de capital, tales como la fabricación de productos metálicos $(9.5 \%)$, maquinaria y equipo (10.6\%), y maquinaria y aparatos eléctricos $(13.5 \%)$.

En el caso de México, la manufactura a través de la maquila de exportación, ocupó un lugar clave en el nuevo modelo de crecimiento, basado en la apertura comercial y la desregulación económica, por lo que los estudios existentes suelen destacar fases diferenciadas en su desarrollo, y en algunos casos incluso, separar los resultados obtenidos por los sectores maquilador y no maquilador tras las reformas. Capdevielle (2005) señala que, mientras bajo la sustitución de importaciones y hasta inicios de los años ochenta, existió una sincronía entre el quehacer de las manufacturas y el de la económica en su conjunto, a partir de finales de los ochenta y tras un periodo de transición, la emergencia de la actividad maquiladora, con altas tasas de crecimiento del producto y del empleo, pero con bajas tasas de productividad, amplió las brechas y asimetrías estructurales en el sector. Holland y Porcile (2005) calculan un pobre desempeño de la tasa de crecimiento de la productividad laboral en las industrias mexicanas, a partir de los años noventa, a diferencia de la

\footnotetext{
${ }^{4}$ Este rápido impacto positivo viene antes de un declive temporal seguido finalmente por un incremento definitivo y permanente.
} 
tendencia experimentada por el resto de los países latinoamericanos, siendo que ésta pasa de $5.6 \%$ en 1980-1990 a -4.4\% en 1990-1999, para recalar en un $0.8 \%$ en los años que van de 1999 a 2002.

$\mathrm{Al}$ igual que en el caso de la India, son pocos los estudios recientes que analizan de forma desagregada, el comportamiento de la productividad laboral en las actividades manufactureras. Vázquez-López (2012) estima aumentos de $2.5 \%$ y $2.8 \%$ en promedio anual, para el conjunto del sector, en los lapsos 1994-2001 y 2001-2008, destacando en el segundo periodo en cuestión, altas tasas de crecimiento en las ramas de las industrias metálicas básicas (15.4\%), debido al incremento de los precios de las materias primas asociadas a la actividad, y en la de fabricación de sustancias químicas básicas (10.6\%). A un nivel mayor de desagregación, calcula disminuciones del indicador, entre 1994 y 2008, en 77 de las 200 clases consideradas, hecho asociado al desplazamiento de productos nacionales por importaciones en el mercado local, lo que apunta en dirección de un auténtico proceso de desindustrialización en una gran parte de la estructura de fabricación.

En lo referente a los determinantes de las evoluciones observadas, a través de técnicas genéricas de tipo diferencial-estructural, como la que se utiliza en el presente trabajo, la Comisión Económica para América Latina y El Caribe (2007) estima que, mientras en el periodo 1960-2003, los incrementos en la productividad laboral de la manufactura estuvieron asociados, tanto al desplazamiento de trabajadores en dirección de usos más eficientes (efecto estructural), como a mejoras técnicas y organizativas al interior de cada una de las industrias (efecto intrínseco), al considerar solamente el periodo post apertura (1985-2001), resulta que a imagen del resto de la economía nacional y a diferencia de los otros países de la región, el componente intrínseco tuvo un aporte negativo a la evolución del indicador. Este resultado es por demás revelador, y apunta hacia una ausencia de inversiones tendientes a incrementar la capacidad de fabricación. Por su parte y contrariamente, Holland y Porcile (2005) encuentran contribuciones positivas del efecto intrínseco, a todo lo largo del lapso 1970-2000, destacando en sus estimaciones, un aporte negativo del efecto de interacción, asociado a la reasignación de trabajadores hacia industrias donde la productividad está creciendo, en cada uno de los decenios del periodo considerado, y particularmente en los años noventa $(-1.26 \%,-3.31 \%$ y $-8.44 \%$ respectivamente).

Capdevielle explica la posible contribución positiva del componente intrínseco en los años 1988-2003, por un aumento de la productividad laboral en las actividades no maquiladoras, ajeno a mejoras técnicas y organizativas, y que: “... pudo haber tenido su origen en procesos de racionalización de personal en un contexto en que la apertura comercial intensificaba la disputa por los mercados locales" (2005, p.115). En síntesis y aun considerando las fuertes discrepancias existentes en los resultados estadísticos obtenidos por distintos autores, los estudios estructurales disponibles de la evolución de la productividad en la industria mexicana señalan un pobre desempeño del indicador, así como el escaso aporte tanto del cambio estructural, como de las transformaciones técnicas y organizativas, a la eficiencia del aparato de fabricación a raíz de la entrada en vigor de las reformas económicas.

Finalmente, los estudios comparativos más recientes que examinan con técnicas similares, el tema del cambio estructural en diversos países en desarrollo, suelen tener por objetivo analizar de forma mucho más agregada, el efecto del desplazamiento del factor trabajo entre grandes sectores y en especial, el paso de trabajadores de la agricultura hacia la industria y/o el sector servicios, con el fin de establecer patrones o tipologías de desarrollo a partir de un mayor número de casos. A manera de ejemplos, McMillan y Rodrik (2014) encuentran para los casos de África y América Latina, en el periodo 1990-2005, contrariamente a lo sostenido por diversos estudios micro 
fundamentados que sostienen un aumento de la eficiencia en las manufacturas debido a la racionalización de sus operaciones con motivo de la liberalización comercial, que las reformas no parecen haber impulsado un cambio estructural con efectos positivos sobre la productividad laboral, debido al desplazamiento de trabajadores de actividades de mayor eficiencia en dirección de otras de menor productividad, incluyendo notablemente, la informalidad. Los resultados de la aplicación de una metodología diferencial-estructural, similar a la utilizada en este trabajo, para 38 países (29 de los cuales son economías en desarrollo) y 9 grandes divisiones de actividad, muestran un incremento anual de la productividad laboral en América Latina de $1.35 \%$ (por $3.87 \%$ en Asia, $4.23 \%$ en India y $1.07 \%$ en México), con contribuciones de $2.24 \%$ del efecto intrínseco (por $3.31 \%$ en Asia), y de $-0.88 \%$ del efecto estructural (por $0.57 \%$ en Asia, $1.06 \%$ en India y $0.23 \%$ en México).

Por su parte, McMillan y Rodrik (2017), al examinar los casos de siete países en desarrollo, utilizando el mismo tipo de técnica y grado de desagregación, encuentran una contribución positiva del cambio estructural al crecimiento de la productividad laboral en India durante la década posterior a las reformas de 1991. Este resultado se explica principalmente por la expansión del sector financiero y de negocios, concomitante de un aporte negativo del efecto estructural, por parte de la manufactura en el lapso 2000-2004. Los autores resaltan la insuficiente acumulación de capacidades (educación, infraestructura y gobernanza), en la tendencia reciente de crecimiento del país, basado en los servicios relacionados con las tecnologías de la información y la subcontratación de procesos de negocios, actividades dinámicas, con elevados niveles de productividad, intensivas en trabajo calificado, pero que no generan una gran cantidad de empleos. En sus ejercicios, los resultados de la técnica diferencial-estructural arrojan un incremento anual de la productividad laboral de $2.9 \%$, entre 1990 y 1999, y de $6.5 \%$, entre 2000 y 2004, pero una preocupante reducción de la contribución del efecto estructural de $1.3 \%$ a $0.3 \%$ al comparar dichos periodos.

\section{DATOS Y METODOLOGÍA}

Con el fin de poder comparar las transformaciones estructurales ocurridas en el sector industrial, a partir de las reformas económicas implementadas en México e India, el autor ha construido una base de datos con series anuales para la producción, el valor agregado, el empleo (número de empleados), y la productividad laboral (valor agregado/número de empleados). Tras revisar las diversas fuentes de información existentes a nivel internacional, se ha optado por extraer los datos de la base estadística, Indstat 4 edición 2012 (United Nations Industrial Development Organization, 2012), elaborada por la UNIDO, bajo la clasificación ISIC rev. 3, tomando por criterios principales, la mayor cantidad de datos comparables disponibles para ambos países, así como el mayor nivel de desagregación en grupos industriales de los mismos. Al ser construida a partir de encuestas industriales nacionales, esta fuente tiene una gran cantidad de vacíos e inconsistencias, por lo que en los casos en los que fue posible, se procedió a completar la información faltante a partir de dos fuentes secundarias adicionales: La Encuesta Industrial Mensual (EIM), bajo la Clasificación Mexicana de Actividades y Productos (CMAP), del Instituto Nacional de Estadística y Geografía (INEGI) para México, y la Annual Survey of Industries (ASI)., elaborada por el Ministry of Statistics and Programme Implementation (2012), para la India.

Tras dicho procedimiento, la base de información retenida conserva las categorías establecidas por la fuente original, en términos de la clasificación ISIC rev.3, y consta para los ejercicios realizados, con datos para un periodo de estudio de 1994 a 2007, en el caso mexicano, con cifras de 90 categorías industriales a cuatro dígitos, y 22 a un nivel de tres dígitos. En el caso de la India, 
el lapso de análisis es de 1998 a 2007, y cuenta con cifras para 123 categorías a cuatro dígitos, y 24 a un nivel de tres dígitos. Mientras que para la India, la base utilizada incluye todos los datos mencionados, de forma anual, para el periodo en cuestión, para México han sido omitidas tres observaciones faltantes relativas al valor agregado del año 2003 de las categorías, 3 312, Medición y prueba de instrumentos de navegación, 351, Construcción y reparación de barcos y botes y, 3 511 , Construcción y reparación de barcos, ninguna de las cuales es relevante en cuanto a su peso en la estructura productiva.

A diferencia de otros trabajos (McMillan y Rodrik, 2014, 2017) que a pesar de reconocer la necesidad de realizar este tipo de análisis al mayor nivel de desagregación posible, por los elevados grados de heterogeneidad presentes a nivel intraindustrial5, optan por mostrar sus resultados en categorías muy agregadas y a precios constantes, los datos presentados a continuación están en dólares de los Estados Unidos, a precios corrientes, debido a la inexistencia de series de deflactores adecuados, a un nivel de desagregación de 4 dígitos de la ISIC rev.3, para ambos países. En este sentido, se previene al lector de que las variaciones en los niveles de productividad laboral obtenidos, se ven afectados por el comportamiento de los precios en el tiempo, sin embargo, la opción de deflactar los valores con los índices existentes a nivel de 12 categorías industriales, causaría en contrapartida sesgos, que anularían la validez de un análisis a mayor nivel de desagregación, con motivo de la alta heterogeneidad sectorial existente en estos países antes destacada.

En lo referente a los determinantes de las evoluciones observadas, la utilización de una técnica genérica de tipo diferencial-estructural permite descomponer el origen de los cambios en la productividad laboral en los lapsos de estudio (1994-2007 para México y 1998-2007 para India) (efecto total) en dos efectos, uno asociado al desplazamiento del factor trabajo entre actividades con distintos niveles de eficiencia (efecto estructural), y otro, atribuible a las mejoras tecnológicas y organizativas que se producen al interior de cada una de las actividades (efecto intrínseco).

La formulación matemática de esta descomposición es la siguiente:

$$
\left(P^{T}-P^{0}\right)=\sum_{i=1}^{n}\left[\left(P_{i}^{T}-P_{i}^{0}\right) \cdot \| \frac{\left(S_{i}^{0}+S_{i}^{T}\right)}{2}\right]+\sum_{i=1}^{n}\left[\left(S_{i}^{T}-S_{I}^{0}\right) \cdot \frac{\left(P_{i}^{0}+P_{i}^{T}\right)}{2}\right]
$$

Donde $\mathrm{P}_{\mathrm{i}}{ }^{\mathrm{t}}$ es la productividad en la actividad $\mathrm{i}(\mathrm{i}=1,2, \ldots \mathrm{n})$ en el instante $\mathrm{t}=0, \mathrm{~T}$ y $\mathrm{S}_{\mathrm{i}}{ }^{\mathrm{t}}$ es la participación de la actividad $\mathrm{i}(\mathrm{i}=1,2, \ldots \mathrm{n})$ en la población activa total empleada en el sector en $\mathrm{t}=$ 0,T, siendo 0 el año inicial de la serie (1997 para la India y 1994 para México), y T, el año final de la misma (2007 en ambos casos). El primer término del lado derecho de la ecuación representa la variación de la productividad laboral ligada a los cambios ocurridos al interior de cada una de las n

\footnotetext{
${ }^{5}$ En este sentido, McMillan y Rodrik (2014, p.17) señalan que: "La mayoría de las industrias en el mundo en desarrollo son una colección de empresas pequeñas, típicamente informales que operan con bajos niveles de productividad, junto a empresas más grandes, altamente productivas que están mejor organizadas y utilizan tecnología más avanzada." Y más adelante, aceptan que: "Nuestros datos son demasiado agregados para capturar los detalles finos de la mala asignación de recursos al interior de sectores industriales... (pero) nos permiten realizar comparaciones entre un mayor número de países en desarrollo” (2014, p.18).
} 
clases de actividad y puede ser asociada al progreso técnico (efecto intrínseco). El segundo término indica el aporte de la recomposición de la fuerza de trabajo al aumento de la productividad (efecto estructural) (Comisión Económica para América Latina y El Caribe, 2007)

Si bien la metodología permite la comparación de los rasgos estructurales de países con distintos grados de crecimiento, una importante limitación es que no genera estimaciones predictivas de la evolución futura, ni de la sostenibilidad de las tendencias observadas, en el contexto de características estructurales contrafactuales (Timmer, 1988). Cabe señalar, no obstante, que los resultados arrojados por las muy diversas aplicaciones de la metodología no han sido a la fecha refutados sólidamente, y en muchos casos, han servido como eficientes herramientas de predicción y planificación (Hellman, 1976). Timmer y De Vries (2009) agregan que el método es limitado porque asume que el desplazamiento de trabajadores, entre actividades, no afecta la productividad laboral de las mismas, haciendo referencia a la necesidad de tomar en cuenta los niveles de productividad marginal y rendimientos a escala crecientes. En este punto, Roncolato y Kucera (2014), basándose en las ideas seminales de Kaldor, señalan que la estimación del efecto de reubicación del empleo, resultante exclusivamente de las diferencias existentes en materia de productividad entre las actividades, es en sí mismo digno de tomarse en cuenta y consistente con la teoría keynesiana. En efecto, desde cierta perspectiva teórica, estos efectos de reubicación pueden incluir economías estáticas y dinámicas de escala, al interior de las actividades, y entre los distintos sectores, economías que difícilmente pueden ser calculadas de todas formas por otros métodos más sofisticados.

\section{CoNCENTRACIÓN PRODUGTIVA Y HETEROGENEIDAD ESTRUCTURAL}

En una primera aproximación a la evolución industrial en ambos países, se observa un mayor dinamismo en la India, siendo que la tasa de crecimiento en promedio anual del valor agregado, es considerablemente superior en este país, al comparar los periodos analizados $(14.3 \%$ por $5.6 \%$ en México). Significativamente, mientras en 1998, el sector generaba 18.9 \% más valor en México, a partir de 2005, este orden se invierte, y para 2007, el valor añadido por la industria de la india es superior en $43.9 \%$ al mexicano (véase gráfica 1). Lo anterior se explica en parte por el fuerte desarrollo de las empresas farmacéutica, cementera, y en particular de la refinación de productos petroleros, en la nación asiática, que pasan a ocupar un lugar preponderante en la estructura y en la articulación productiva. En cuanto a México, es de señalar la progresiva pérdida de peso relativo de la industria automotriz, particularmente de la fabricación de motores a partir de 2000, y en contraposición con el caso de la India, el escaso desarrollo de la refinación petrolera, a pesar de la condición estratégica de dicha actividad, y de la abundante disponibilidad del energético en el país.

En términos generales, mientras en la India, las tendencias mencionadas pudieran asociarse con una transformación significativa, en lo relativo al peso de las diferentes industrias al comparar los datos de 1979/80 con los de 1997-1998, a diferencia de lo observado por Unel (2003) para el lapso anterior. Para el caso de México, Vázquez-López (2012) postula en calidad de hipótesis, basándose en el nulo aporte al incremento de la productividad laboral, del desplazamiento de trabajadores de actividades de baja eficiencia a otras más modernas, la ausencia de un cambio

\footnotetext{
${ }^{6}$ Los valores de los efectos en el caso de las ramas, a 3 dígitos de la clasificación ISIC rev.3, han sido calculados mediante la suma de los valores de los efectos de las clases de actividad que cada una de estas ramas incluye con el fin de evitar discrepancias estadísticas.
} 


\section{GRÁFICA 1. VALOR AGREGADO INDUSTRIAL EN INDIA Y MÉXICO, 1998-2007 (DÓLARES CORRIENTES)}

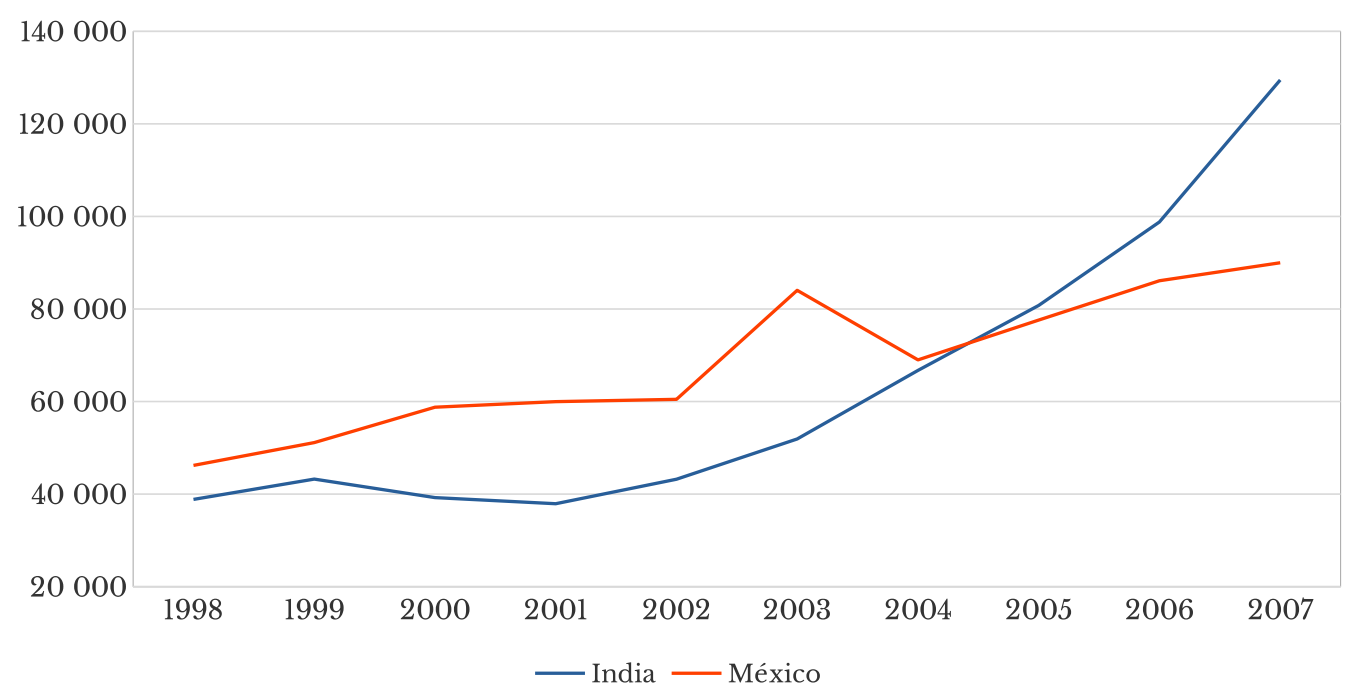

Fuente: Elaboración propia con datos de United Nations Industrial Development Organization (2012). INDSTAT 4 Database.

estructural en la manufactura, a pesar de las reformas económicas implementadas y de las transformaciones ocurridas en el sector. En ambos países existe, no obstante, una clara tendencia a la especialización productiva y a la concentración de la actividad en un número reducido de ramas. A un nivel de cuatro dígitos, las cinco principales categorías de la base de información pasaron de representar en su conjunto, en términos de valor agregado, $30.9 \%$ del total sectorial generado en 1998 en India y 29 \% en 1994 en México, a 40.7 \% y 35.9 \% en 2007 respectivamente.

La mayor concentración de la actividad, fruto de un patrón de producción más especializado, tuvo por corolario un incremento de la eficiencia sectorial en su conjunto. Nuestras estimaciones confirman un aumento de la productividad laboral, en los periodos considerados, a tasas de $6.4 \%$ anual en México, y de 14.7 \% en los mismos términos en India. Es de mencionar sin embargo que, a pesar del mayor ritmo de modernización en la nación asiática, la brecha sigue siendo considerable entre los países en 2007, siendo que el indicador mexicano es superior en seis veces al de la India. A nivel desagregado, en las dos naciones, destaca el incremento de la productividad laboral en la refinación petrolera que se explica fundamentalmente por el fuerte aumento de los precios del energético en los años en cuestión. A grandes rasgos, mientras en el país latinoamericano, solo una de las principales actividades, registra una tasa de incremento del indicador mayor a $10 \%$ ( $17.1 \%$ en la química básica), en la nación asiática, casi todas las categorías, con cierto peso en la estructura, cumplen con este requisito, destacándose las industrias, cementera (29.4\%), de los refrescos $(26.7 \%)$, de fabricación de metales preciosos y metales no ferrosos, y del hierro y el acero $(23.1 \%)$, entre otras (véanse cuadro 1 y 2 ).

A manera de recuento, al comparar los datos de los años iniciales, y últimos de los periodos considerados, en el caso de la India, 80 de las 123 categorías presentes en la base de información, es decir $83 \%$ del valor agregado total generado por la industria en 2007 , tuvieron tasas de 
GUADRO 1. PRODUCTIVIDAD LABORAL EN LAS PRINCIPALES INDUSTRIAS DE MÉXICO, 1994 Y 2007 (DÓLARES CORRIENTES POR EMPLEADO Y PORCENTAJES).

\begin{tabular}{|c|c|c|c|c|}
\hline $\begin{array}{l}\text { Código ISIC } \\
\quad \text { rev. } 3\end{array}$ & Descripción & 1994 & 2007 & $\begin{array}{l}\text { Crecimiento } \\
\text { anual* }^{*}\end{array}$ \\
\hline 1549 & $\begin{array}{l}\text { Elaboración de otros productos } \\
\text { alimenticios }\end{array}$ & 82395 & 247588 & 8.8 \\
\hline 1551 & $\begin{array}{l}\text { Destilación, rectificación y mezcla } \\
\text { de bebidas alcohólicas }\end{array}$ & 130072 & 325346 & 7.3 \\
\hline 1554 & Elaboración de bebidas no alcohólicas & 23362 & 55480 & 6.9 \\
\hline 1600 & Elaboración de productos del tabaco & 286604 & 625335 & 6.2 \\
\hline 2320 & $\begin{array}{l}\text { Fabricación de productos de la } \\
\text { refinación petrolera } \\
\text { Fabricación de sustancias químicas }\end{array}$ & 52501 & 1481860 & 29.3 \\
\hline 2411 & básicas & 60502 & 470769 & 17.1 \\
\hline 2423 & Fabricación de productos farmacéuticos & 46114 & 109906 & 6.9 \\
\hline 2694 & Fabricación de cemento, cal y yeso & 101619 & 315782 & 9.1 \\
\hline 2710 & Industrias básicas del hierro y el acero & 56981 & 132187 & 6.7 \\
\hline 3410 & Fabricación de vehículos automotores & 67316 & 121582 & 4.7 \\
\hline Total del sector & & 32955 & 74227 & 6.4 \\
\hline
\end{tabular}

*Tasa de crecimiento promedio anual geométrica

Fuente: Elaboración propia con datos de United Nations Industrial Development Organization (2012). INDSTAT 4 Database.

incremento de su productividad laboral superiores a $10 \%$ en promedio anual, siendo solamente cinco las que experimentaron descensos en las mismas. Por el contrario, en México, tan solo 9 de las 90 categorías, que significan $16.9 \%$ del valor añadido sectorial total en 2007 , cumplieron con dicho criterio, y un mayor número de clases industriales (11), registraron disminuciones en el indicador. A este grado de desagregación, los resultados obtenidos muestran un proceso relativo de modernización y reestructuración productiva en la India, si bien con cierto rezago en el tiempo y numerosas asimetrías, y un proceso involutivo en México.

Asimismo, los datos permiten confirmar para un periodo más reciente, lo observado por Unel (2003) para el lapso 1979-1997, en lo referente a la baja participación en el valor agregado manufacturero de la India, de las industrias con peor desempeño en cuanto a productividad. Las cinco categorías, cuyo indicador experimentó una reducción en nuestra base de información, representan solamente $0.32 \%$ del valor añadido total en 2007 , cifra muy inferior a la presentada por Pattnayak y Thangavelu (2001) para la TFP entre 1991 y 1997 (43\%). A su vez, las 43 clases, con tasas de incremento de la productividad laboral inferiores a $10 \%$ en promedio anual, suman $17.3 \%$ del valor agregado total en ese año. En concordancia con los resultados obtenidos por varios autores para este país, se verifican también diferencias considerables en la evolución de las distintas industrias, y la existencia de una amplia brecha en términos de eficiencia entre las mismas, 
CUADRO 2. PRODUCTIVIDAD LABORAL EN LAS PRINCIPALES INDUSTRIAS DE INDIA, 1998 Y 2007 (DÓLARES CORRIENTES POR EMPLEADO Y PORCENTAJES)

\begin{tabular}{|c|c|c|c|c|}
\hline $\begin{array}{c}\text { Código ISIC } \\
\text { rev. } 3\end{array}$ & Descripción & 1998 & 2007 & $\begin{array}{c}\text { Crecimiento } \\
\text { anual }^{*}\end{array}$ \\
\hline 1554 & Elaboración de bebidas no alcohólicas & 6302 & 33014 & 26.7 \\
\hline 1711 & Preparación e hilatura de fibras textiles & 2674 & 5212 & 10 \\
\hline 2320 & $\begin{array}{l}\text { Fabricación de productos de la refinación } \\
\text { petrolera } \\
\text { Fabricación de plásticos en formas }\end{array}$ & 35553 & 217242 & 29.5 \\
\hline 2413 & primarias & 59679 & 87916 & 5.7 \\
\hline 2423 & Fabricación de productos farmacéuticos & 8482 & 17151 & 10.6 \\
\hline 2694 & Fabricación de cemento, cal y yeso & 9562 & 58072 & 29.4 \\
\hline 2710 & Industrias básicas del hierro y el acero & 9183 & 34767 & 20.9 \\
\hline 2720 & $\begin{array}{l}\text { Fabricación de productos primarios de } \\
\text { metales preciosos y metales no ferrosos }\end{array}$ & 9642 & 41307 & 23.1 \\
\hline 3410 & Fabricación de vehículos automotores & 9829 & 35084 & 19.9 \\
\hline Total del sector & & 4937 & 12917 & 14.7 \\
\hline
\end{tabular}

*Tasa de crecimiento promedio anual geométrica

Fuente: Elaboración propia con datos de United Nations Industrial Development Organization (2012). INDSTAT 4 Database.

generalmente atribuida a la entrada de inversión extranjera directa (IED), y nuevas tecnologías, en determinadas actividades tras las reformas económicas (Bhagavan, 1995; Kim y Saravanakumar, 2012; Patynayak y Thangavelu, 2001).

En un contexto de especialización productiva doméstica y apertura externa crecientes, la ampliación de las brechas existentes, en términos de eficiencia, entre las distintas categorías industriales, es incluso superior en México, producto por un lado, de una modernización tecnológica y organizativa, limitada a determinadas actividades "líderes", y por otro, de la quiebra de industrias enteras, sumidas en auténticos procesos de desindustrialización, tradicionalmente dedicadas a proveer al mercado interno de productos finales e insumos, e incapaces de competir con las importaciones en el nuevo contexto. De hecho, al calcular los indicadores estadísticos tradicionales de dispersión, en las series de productividad laboral, la tendencia al alza de la heterogeneidad estructural es clara a partir de 1999, siendo el incremento del coeficiente de variación de las mismas, de $28.2 \%$ en la India, y de 144 \% en México, al comparar 1998 y 2007 (véase gráfico 2). En el caso de la India, Kim y Saravanakumar (2012) responsabilizan de la existencia de estas brechas, a una estructura compuesta por un pequeño número de grandes empresas eficientes muy tecnificadas, y de una gran cantidad de PYMES ineficientes y con tecnología atrasada. Por su parte, Bhagavan (1995) analiza los orígenes de esta polarización, tras las medidas implementadas, como el resultado de varios conflictos latentes, entre los que destaca la pugna entre el capital doméstico y el extranjero. 


\section{GRÁFICA 2. COEFICIENTE DE VARIACIÓN DE LA PRODUCTIVIDAD LABORAL INDUSTRIAL EN INDIA Y MÉXICO, 1998-2007}

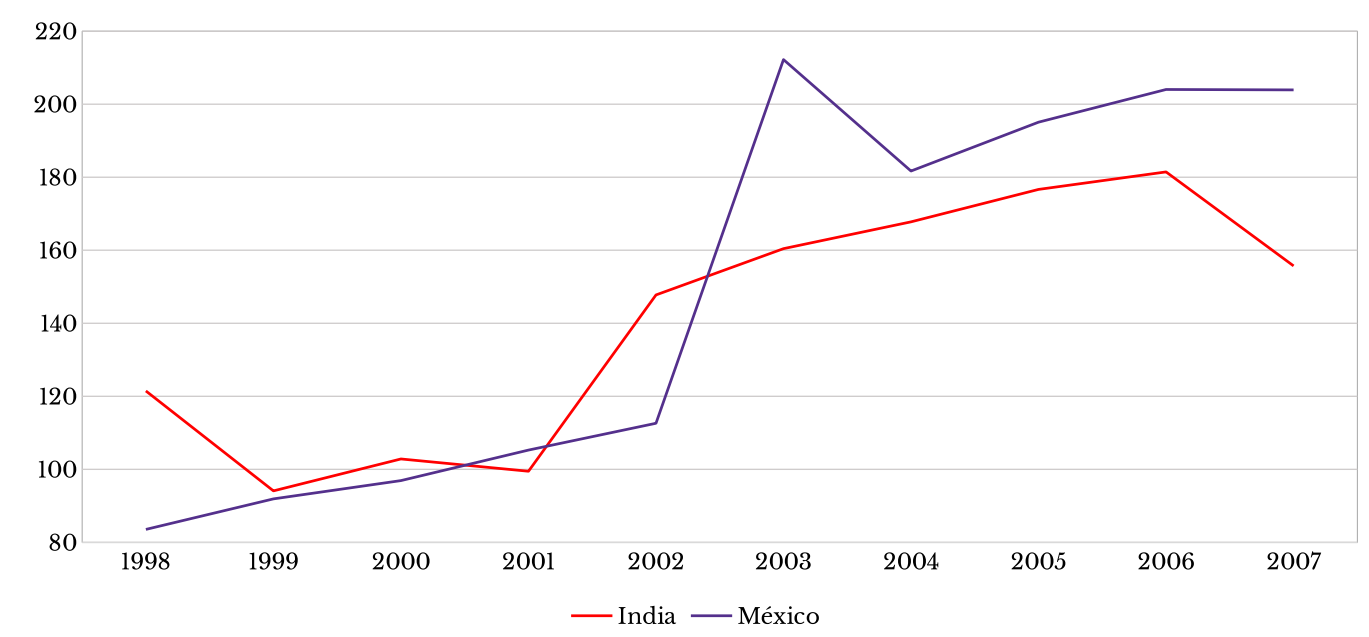

Fuente: Elaboración propia con datos de United Nations Industrial Development Organization (2012). INDSTAT 4 Database.

$\mathrm{Al}$ respecto, el tejido asimétrico del sector en México, se asemeja en estas características al de la nación asiática, con la particularidad de que las autoridades profundizaron el proceso de reformas a un ritmo más rápido, afectando una estructura industrial madura y comparativamente más moderna. Hanson (2010) califica de "agresivo" el ritmo, tanto de la reducción del rol del Estado en la economía, como del proceso de integración en mercado globales de México, y subraya que el país fue el primero en implementar las medidas en América Latina, y lo hizo, una década antes que las naciones de Europa del este. A manera de ejemplo, menciona que en el espacio de unos cuantos años, se privatizaron cerca de 1000 empresas paraestatales, incluyendo el monopolio telefónico, TELMEX, y la mayoría de los bancos, y asienta que para la entrada en vigor del TLCAN, en 1994, la transformación estructural, encabezada a nivel del gobierno, por tecnócratas entrenados en los E.U., había sido completa. De hecho, Kuczynksi y Williamson (2003), como muchos otros autores, califican la política económica del país en esos años, de ejemplar en términos de la aplicación de los lineamientos del Consenso de Washington.

En contraposición, India, estableció las reformas más tarde, a partir de 1991, en medio de una severa crisis de la balanza de pagos, y lo hizo, con una estrategia calificada de "gradualista", que llevó incluso a diversos autores, al punto de atribuir los primeros fracasos del proceso, a un ritmo excesivamente lento y "frustrante", de implementación de las medidas. A manera de ejemplo, Ahluwalia (2002) señala que el gobierno adoptó un acercamiento limitado de vender solamente participaciones minoritarias en empresas públicas, manteniendo así, el control de las mismas, en una política de "desinversión”, en oposición a una política de abierta "privatización”. Para esta autora, el "gradualismo" implicó una clara definición de los objetivos de las reformas, pero una deliberada elección de extender el tiempo de aplicación de las mismas, para minimizar la oposición política y reducir el costo económico de la transición. La idea era entonces reducir las controver- 
sias y las divisiones políticas, y permitir la construcción de un consenso por etapas en torno a las medidas, sin embargo, muchos grupos de interés participaron en el entendido de que las medidas no irían demasiado lejos.

\section{RESULTADOS DE LA TÉGNICA DIFERENCIAL-ESTRUCTURAL}

Los hallazgos de la aplicación de la metodología diferencial-estructural señalan, para ambos países, un nulo aporte del efecto estructural al crecimiento del indicador sectorial, en los periodos de estudio, siendo que el desplazamiento de trabajadores de usos menos eficientes en dirección de actividades de mayor productividad, no se produjo a un nivel agregado tras las reformas económicas. Bhat (2013) asocia este resultado, previsible en el caso mexicano, a la ausencia en India, de un impacto considerable de las medidas aplicadas sobre el comportamiento de la fuerza de trabajo, debido a toda una serie de distorsiones estructurales a diferentes niveles, tales como el reducido tamaño de las empresas, bajas escalas de producción, pobre integración y alta concentración del mercado local, y persistencia de la propiedad estatal. Su argumento se inserta en el marco de un proceso de crecimiento que, si bien ha evitado la desindustrialización propia de otras naciones, se ha dado sin creación de empleos adicionales. En este orden de ideas, las estimaciones de Virmani y Hashim (2011) confirman una fuerte caída de la parte del factor trabajo en el valor agregado manufacturero en el periodo 1991-1992 a 2007-2008 (3.4\% en promedio anual para el conjunto del sector y, $6.2 \%$ y $4.1 \%$, en las industrias de otros equipos de transporte, y de vehículos y camiones motores, respectivamente en los mismos términos).

En consecuencia, el efecto intrínseco, atribuible a procesos de modernización tecnológica y organizativa al interior de cada actividad, explica la totalidad de las mejoras de eficiencia (100.7\% en México y 99 \% en India). Es de notar, una pequeña contribución del efecto estructural, en las diez industrias de mayor aporte al desempeño de la productividad laboral sectorial $(7.3 \%$ del efecto total de las mismas en su conjunto en India y $3.4 \%$ en México), opacado por la expulsión de trabajadores en el resto de las categorías (véase gráfico 3). Estos hallazgos son consistentes con los obtenidos por trabajos anteriores. Para la India, Kim y Saravanakumar (2012) encuentran que, el progreso técnico es el principal determinante de los incrementos en la TFP en el lapso 2000-2006. En lo referente a México, si bien los resultados no son homogéneos, Capdevielle (2005) estima para el periodo 1988-2003, un efecto de reasignación de trabajadores y de interacción negativo, es decir que el componente intrínseco explica más de la totalidad del aumento registrado en la productividad laboral en su ejercicio.

Un segundo aspecto resultante está relacionado con la elevada concentración de los procesos de modernización en un número reducido de actividades. Mientras en la India, 10 de las 123 industrias, a cuatro dígitos de la clasificación ISIC rev. 3, son responsables del $62.7 \%$ del incremento en el indicador, en México, 10 de las 90 explican el 67.3\%. De hecho, tan solo cinco códigos contribuyen con $50.9 \%$ de las mejoras de eficiencia en India, y con $45.7 \%$ de las mismas en el país latinoamericano (véanse cuadros 3 y 4 y gráfico 3). En este sentido, los resultados permiten confirmar que independientemente de las diferencias en las transformaciones ocurridas, en ambas naciones, las reformas económicas han profundizado las asimetrías existentes, e impulsado un desarrollo productivo limitado a las actividades de mayor inserción global.

Ya en 2001, al evaluar los primeros efectos de las medidas aplicadas, Pattnayak y Thangavelu (2001) afirmaban para el caso del país asiático que las ganancias de productividad no se distribuían homogéneamente entre las industrias, debido a muy diversos grados de adopción de las 


\section{CUADRO 3. DETERMINANTES DE LA PRODUCTIVIDAD LABORAL EN LAS PRINCIPALES INDUSTRIAS DE MÉXICO, 1994-2007 (DÓLARES CORRIENTES POR EMPLEADO)}

\begin{tabular}{|c|c|c|c|c|}
\hline $\begin{array}{l}\text { Código ISIC } \\
\text { rev.3 }\end{array}$ & Descripción & \multicolumn{3}{|c|}{ Efectos } \\
\hline 1520 & $\begin{array}{l}\text { Elaboración de productos lácteos } \\
\text { Elaboración de otros productos }\end{array}$ & 1118.5 & 528.8 & 1647.4 \\
\hline 1549 & alimenticios & 2013.2 & 232.5 & 2245.7 \\
\hline 1554 & $\begin{array}{l}\text { Elaboración de bebidas no alcohólicas } \\
\text { Fabricación de productos de la }\end{array}$ & 1887 & -203.8 & 1683.1 \\
\hline 2320 & $\begin{array}{l}\text { refinación petrolera } \\
\text { Fabricación de sustancias químicas }\end{array}$ & 5607.5 & 377.8 & 5985.3 \\
\hline 2411 & básicas & 4916.9 & -945 & 3971.9 \\
\hline 2423 & Fabricación de productos farmacéuticos & 2291.1 & 670.8 & 2961.9 \\
\hline 2694 & Fabricación de cemento, cal y yeso & 2374.6 & -864.2 & 1510.4 \\
\hline 2710 & Industrias básicas del hierro y el acero & 2041.9 & 189.3 & 2231.2 \\
\hline 3410 & Fabricación de vehículos automotores & 3220.6 & 475.1 & 3695.6 \\
\hline 3430 & $\begin{array}{l}\text { Fabricación de partes, piezas y accesorios } \\
\text { para vehículos automotores }\end{array}$ & 1392.6 & 440.8 & 1833.4 \\
\hline \multicolumn{2}{|c|}{ Suma de las 10 categorías } & 26863.9 & 902 & 27765.9 \\
\hline \multicolumn{2}{|c|}{ Total del sector } & 41561.3 & -290.2 & 41271.1 \\
\hline
\end{tabular}

Fuente: Elaboración propia con datos de United Nations Industrial Development Organization (2012). INDSTAT 4 Database. 


\section{GRÁFICA 3. DETERMINANTES DE LA PRODUCTIVIDAD LABORAL EN EL SECTOR Y SUS DIEZ PRINCIPALES INDUSTRIAS EN INDIA Y MÉXICO, 1998-2007 (DÓLARES CORRIENTES POR EMPLEADO)}

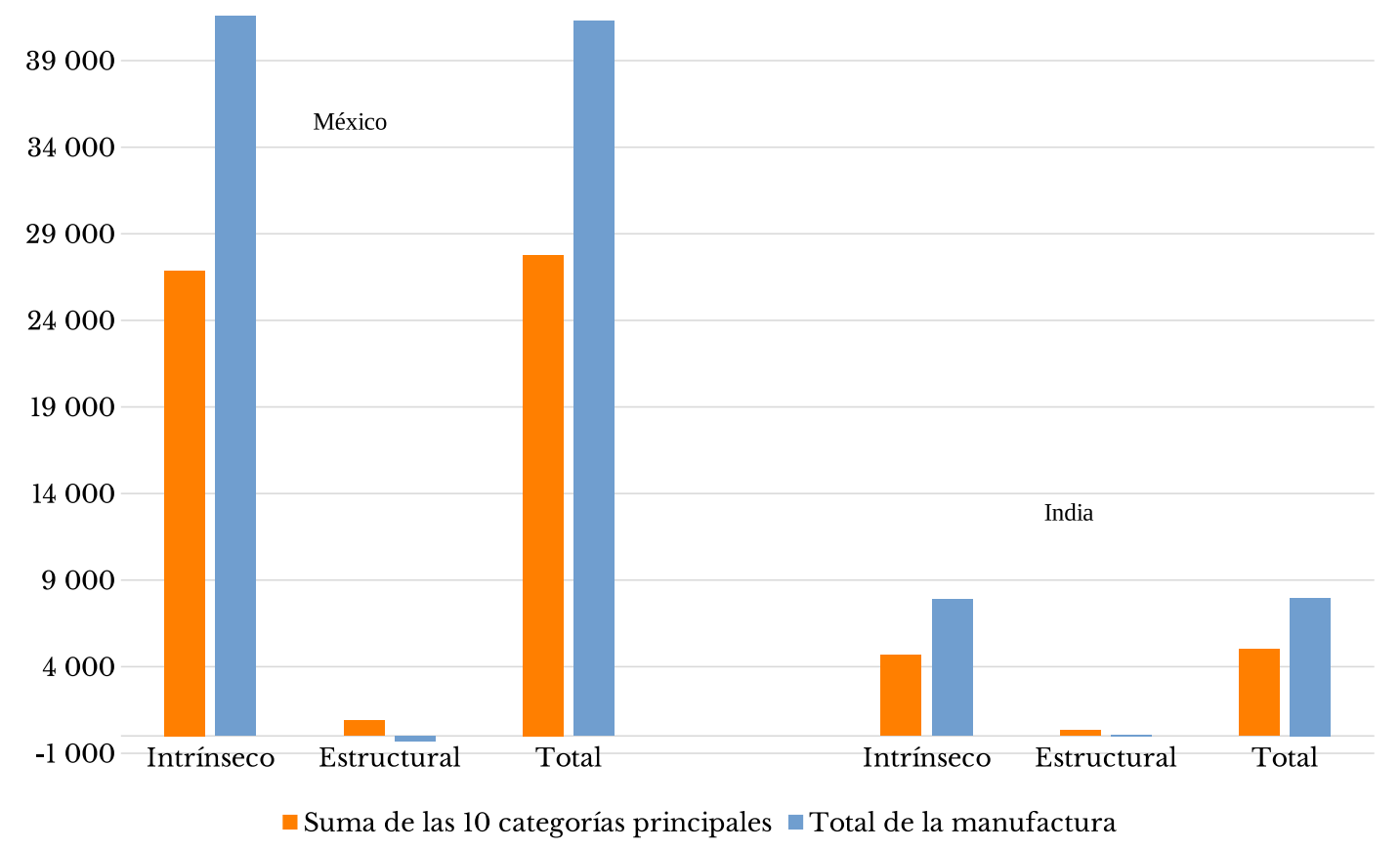

Fuente: Elaboración propia con datos de United Nations Industrial Development Organization (2012). INDSTAT 4 Database.

nuevas tecnologías (en sus cálculos, los 12 códigos de mayor aporte al crecimiento de la TFP (de 70 considerados) explican la totalidad de su aumento en el lapso 1991-1997) (2001, p.13). En lo referente a México, Vázquez-López (2012) vincula esta alta concentración de las prácticas eficientes en unas cuantas grandes empresas insertas en ordenamientos globales, a una escasa difusión del progreso técnico, y estima a partir de encuestas nacionales que 10 clases de actividad de las 200 registradas, son responsables del $72.3 \%$ de los aumentos en el indicador laboral del sector en el periodo 1994-2008. Desde la perspectiva teórica asumida en este trabajo, se asume entonces que en el caso de la manufactura mexicana, la marcada tendencia a la concentración de las técnicas eficientes en un número reducido de industrias, y grandes empresas, con el consiguiente incremento de la heterogeneidad en los niveles de productividad de las distintas actividades, es un proceso de involución que hace más vulnerable al sector y limita a su vez la búsqueda de alternativas de diversificación productiva (Capdevielle, 2005).

A nivel de las diferentes industrias, destaca en nuestras estimaciones, la elevada contribución al crecimiento de la productividad laboral sectorial de la refinación petrolera, de la química básica, y de los vehículos automotores, en el caso mexicano, y de la refinación petrolera, y del hierro y el acero, en la India (ver cuadros 3 y 4). En lo relativo a la refinación petrolera, como ya se ha mencionado, parte de la evolución observada se explica por el fuerte incremento de los precios de los energéticos, en el mercado mundial, en el lapso de análisis, pero es de notar, el contraste existente, en términos de las medidas aplicadas, entre el país asiático y México. En India, la actividad fue 


\section{GUADRO 4. DETERMINANTES DE LA PRODUCTIVIDAD LABORAL EN LAS PRINCIPALES INDUSTRIAS DE INDIA, 1998-2007 (DÓLARES CORRIENTES POR EMPLEADO)}

\begin{tabular}{clrrr}
\hline $\begin{array}{c}\text { Código ISIC } \\
\text { rev.3 }\end{array}$ & \multicolumn{1}{c}{ Descripción } & Efectos & \\
\hline 1554 & Elaboración de bebidas no alcohólicas & 107.9 & 17.3 & 125.3 \\
& Fabricación de productos de la & & & \\
2320 & $\quad$ refinación petrolera & 1194.8 & 255.9 & 1450.7 \\
2423 & Fabricación de productos farmacéuticos & 270.5 & 103 & 373.5 \\
2694 & Fabricación de cemento, cal y yeso & 526.2 & -31 & 495.2 \\
2710 & Industrias básicas del hierro y el acero & 1409.6 & 45.7 & 1455.3 \\
& Fabricación de productos primarios de & & & \\
2720 & $\quad$ metales preciosos y metales no ferrosos & 306.4 & -47 & 259.3 \\
& Fabricación de motores, generadores & & & \\
3110 & y transformadores eléctricos & 179.3 & 7.8 & 187.1 \\
3410 & Fabricación de vehículos automotores & 256.1 & 32.1 & 288.2 \\
& Fabricación de partes, piezas y accesorios & & & \\
3430 & para vehículos automotores & 135.7 & 88.8 & 224.6 \\
3591 & Fabricación de motocicletas & 272.9 & -131.1 & 141.8 \\
& & & & \\
Suma de las 10 categorías & 4659.5 & 341.5 & 5001 \\
Total del sector & & 7898.4 & 82.1 & 7980.5 \\
\hline
\end{tabular}

Fuente: Elaboración propia con datos de United Nations Industrial Development Organization (2012). INDSTAT 4 Database.

incentivada tras las reformas, mediante el establecimiento de niveles tarifarios preferenciales a la importación de crudo, menores a los aplicados a los productos petroleros terminados importados (Virmani y Hashim, 2011).

Por el contrario, en México, los beneficios obtenidos de la extracción de la materia prima, se ven contrarrestados por una producción insuficiente de productos finales que resulta en elevados y onerosos montos de importación de los mismos. Al respecto, una de las primeras medidas gubernamentales, adoptada previo al grueso de las reformas económicas en México en 1986, fue la reclasificación de la petroquímica básica que significó el retiro de la empresa estatal Petróleos Mexicanos (PEMEX) del suministro de estos insumos y, en consecuencia, el encarecimiento de los mismos. A la par, la escasa inversión realizada y el proyecto de fragmentación organizativa en la paraestatal, provocaron la obsolescencia tecnológica de las instalaciones existentes, postergando a su vez a la fecha, la multiplaneada construcción de varias refinerías (Armenta, 2008). Con estos antecedentes, el aporte aquí calculado, de la refinación petrolera al comportamiento de la productividad laboral industrial agregada, en la nación latinoamericana, cuestiona tanto la falta de una mayor inversión en la actividad que extienda la capacidad productiva, como la pretendida falta de rentabilidad de la empresa estatal PEMEX. 
En cuanto a las industrias de la química básica, y de los vehículos automotores, en México, en el primer caso, el resultado se explica por procesos de racionalización productiva, en el contexto de un mercado doméstico controlado por dos grandes conglomerado 7 . De hecho, al comparar el año 2007 con 1994, el número de empleados se redujo en $32.5 \%$, lo que se traduce en un efecto estructural negativo en la actividad (ver cuadro 3). Por su parte, en la industria automotriz, la tendencia está relacionada con el elevado grado de modernización, y progreso técnico, de las plantas ensambladoras establecidas en el país, pero insertas en eslabonamientos globales de valor de empresas transnacionales cuya producción se realiza a partir de componentes importados y se destina al mercado de los Estados Unidos (Álvarez, 2002). Es de señalar entonces, la reducción del contenido nacional en estas actividades, tras la apertura de la economía mexicana, como consecuencia tanto del impacto negativo de estos funcionamientos internacionales sobre los grados de articulación locales, como de la realización de tareas intensivas en mano de obra de baja calificación (Puyana y Romero, 2006).

En lo referente a la India, una explicación de la elevada contribución de la industria básica del hierro y el acero, al desempeño del indicador sectorial, es que estas actividades tenían una relevante participación estatal antes de las reformas, así como restricciones al incremento de su capacidad de fabricación, y se veían limitadas por el licenciamiento de nuevas inversiones, por lo que las medidas aplicadas significaron un aumento de la participación privada en la industria y el rápido crecimiento de la producción con escasa inversión en maquinaria y equipo (Virmani y Hashim, 2011). Se destaca por último que en ambos países, las empresas farmacéuticas y fabricantes de partes y accesorios para automóviles, registran en su conjunto, un efecto estructural positivo de cierta magnitud relativa que encuentra su origen en dinámicas globales particulares.

En el caso de la farmacéutica, las expectativas de comercialización generadas por la liberalización económica de países en vías de desarrollo, con amplios mercados internos, resultaron en estrategias transnacionales que buscaban, entre otros aspectos, cohesionar una red global de sistemas de distribución locales (Greenwald y Kahn, 2005). En México, lo anterior se combina por ejemplo con importantes inversiones en capacitación, tendientes a formar especialistas dedicados a controlar y coordinar varias líneas de productos en forma simultánea (Guzmán y Zúñiga, 2004). En cuanto a la fabricación de partes y accesorios para automóviles, las ensambladoras transnacionales tratan de replicar las estructuras de suministro de insumos de los países donde se encuentra ubicada la casa matriz, requiriendo a los proveedores establecerse mediante esquemas de subcontratación, justo a tiempo, y calidad total, cerca de las nuevas plantas en el extranjero (Álvarez, 2002). En algunas experiencias, estos grandes proveedores globales lograron concentrar funciones en sus nuevas sedes y erigirse en nodos críticos a nivel regional, lo que se tradujo en generación de empleos en estas localizaciones (ver para el caso de Delphi en México, Carrillo y Lara, 2004).

\section{Conclusiones}

Las reformas implementadas a partir de los años ochenta, en India y México, sustentadas en una mayor especialización productiva, y basadas en la desregulación económica, la liberalización comercial, y el retiro del Estado de la conducción de la economía, permitieron elevar los niveles

\footnotetext{
${ }^{7}$ En 2010, las grandes empresas de la química básica representaban solamente $3.3 \%$ del total de unidades encuestadas en su giro, pero su aporte a la producción total de dicho giro era de carácter monopólico (81.7\%) (estimaciones propias con base en Euromonitor International (2012), Base de datos de la herramienta Passport).
} 
de fabricación y productividad laboral del sector industrial en su conjunto. No obstante, el costo de estos avances fue significativo si se consideran los grados crecientes tanto de concentración de la oferta como de heterogeneidad estructural registrados. En ambos casos, se corrobora para los periodos analizados (1994-2007 para México y 1997-2007 para India), una tendencia a la ampliación de las desigualdades entre las diferentes industrias, así como a la concentración de la modernización en un número reducido de actividades. Es de subrayar que estos elementos se encuentran en la actualidad, entre los principales cuellos de botella estructurales, de los aparatos productivos de estos países.

En India, donde el dinamismo fue mayor, este costo se refleja en un crecimiento sectorial sin generación de empleo, aspecto particularmente preocupante en un país con un bono demográfico considerable. En el caso de México, además de la reducción en el número de empleados en el sector, se registraron auténticos procesos de desindustrialización, marcados por la disminución de los niveles de producción en algunas industrias. Desde la perspectiva teórica asumida, semejantes asimetrías están negativamente correlacionadas en el tiempo, con el ritmo de crecimiento de la productividad laboral, y reducen paulatinamente, las posibilidades de eslabonar las diversas actividades limitando el desarrollo de sinergias productivas domésticas, lo que condujo en última instancia, al adelgazamiento de una estructura cada vez más dependiente de las dinámicas globales.

En suma, los resultados obtenidos muestran un proceso relativo de restructuración y modernización productiva, pero sin generación de empleo, y con un cierto rezago en el tiempo, en India, y una evolución más cuestionable en el caso mexicano, derivada de una excesiva especialización dependiente de los funcionamientos transnacionales. Es de notar que en ninguno de los dos casos estudiados se verifica un cambio estructural importante, definido como el desplazamiento del factor trabajo en dirección de usos más eficientes, lo que contradice abiertamente uno de los principales argumentos en favor de la liberalización comercial, y en términos generales, del libre mercado en las condiciones presentes. Una respuesta pudiera residir entonces, en el establecimiento de legislaciones tendientes a limitar los crecientes grados de concentración de la oferta, concomitantes de las estructuras de mercado menos competitivas registradas tras las reformas establecidas.

Por último, es relevante destacar las posibles razones de resultados diferenciados al comparar la evolución industrial en los dos países. Al parecer, un primer elemento explicativo es el ritmo de implementación de las distintas medidas, mientras en India, el proceso gradual pudo haber favorecido el ajuste de ciertas industrias a las nuevas condiciones competitivas, así como el uso productivo de la inversión extranjera, en México, el ritmo acelerado y sin planificación alguna, de la liberalización comercial y de la privatización de empresas estratégicas, resultó en la quiebra de una gran cantidad de PYMES pudiendo haber fomentado hasta cierto punto a su vez, el uso especulativo de los capitales entrantes. Otros aspectos a considerar son entonces las particularidades del desarrollo productivo en cada caso, mientras en India, la liberalización progresiva vino a modernizar un débil tejido industrial en aras de explotar un mercado interno potencialmente grande, en México, las reformas buscaron por el contrario, insertar internacionalmente, sólo algunas actividades de una estructura mucho más diversificada y tecnificada, en función de las necesidades exportadoras cambiantes de cadenas globales de valor (CGV).

En este sentido, las dinámicas mundiales de cada industria, y los requerimientos particulares que emanan de ellas en términos de la explotación de recursos naturales y humanos, así como las expectativas de obtención de rentas por parte de las grandes empresas coordinadoras de CGV en los diferentes mercados, tuvieron un papel definitivo en las transformaciones estructurales experimentadas por estos países. La enseñanza en cuanto a la elección de una estrategia de desarrollo 
económico, en un contexto de globalización creciente, en el caso de los países latinoamericanos, parece apuntar en dirección de la necesidad de contar con un Estado autónomo e independiente de las dinámicas corporativas internacionales. Un entramado institucional democrático, capaz de actuar sobre las formas de inserción económica global, pudiera entonces hacer compatibles las metas del desarrollo productivo y social nacionales de largo plazo, con las necesidades financieras más apremiantes actuales, y en última instancia, con los intereses siempre alienantes de los grandes corporativos transnacionales.

\section{REFERENCIAS}

Ahluwalia, I. J. (1991). Productivity and growth in Indian manufacturing. Delhi ; New York: Oxford University Press.

Ahluwalia, M. S. (2002). Economic Reforms in India Since 1991: Has Gradualism Worked? Journal of Economic Perspectives, 16(3), 67-88. doi: 10.1257/089533002760278721

Álvarez, M. (2002). Cambios en la industria automotriz frente a la globalización: El sector de autopartes en México. Contaduría y Administración, (206), 29-49.

Anima, S., \& Guerrero, V. (2001). El sector público en México: De la sustitución de importaciones a la sustitución de exportaciones. Momento Económico, (117), 35-49.

Armenta, L. (2008). La industria petroquímica y la estrategia de desarrollo industrial en México. Comercio Exterior, 58(10), 697-707.

Bhagavan, R. (1995). Technological Implications of Structural Adjustment: Case of India. Economic and Political Weekly, 30(7-8), 2-12.

Bhagwati, J. N. (1970). India: Planning for industrialization; industrialization and trade policies since 1951. Londres: Oxford University Press.

Bhat, T. (2013). Growth and Structural Changes in Indian Industry. Nueva Delhi: Institute for Studies in Industrial Development.

Bhaumik, S. K., Gangopadhyay, S., \& Krishnan, S. (2009). Reforms and Entry: Some Evidence from the Indian Manufacturing Sector. Review of Development Economics, 13(4), 658-672. doi: 10.1111/j.1467-9361.2009.00519.x

Capdevielle, M. (2005). Globalización, especialización y heterogeneidad estructural en México. En M. Cimoli (Ed.), Heterogeneidad estructural, asimetrías tecnológicas y crecimiento en América Latina (pp. 101-126). Santiago de Chile: Comision Economica para America Latina y El Caribe/Banco Internacional del Desarrollo.

Cárdenas, E. (2003). El proceso de industrialización acelerada en México (1929-1982). En E. Cárdenas, J. A. Ocampo, \& R. Thorp (Eds.), Industrialización y Estado en la América Latina: La leyenda negra de la posguerra (pp. 240-276). México: Fondo de Cultura Económica.

Carrillo, J., \& Lara, A. (2004). Nuevas capacidades de coordinación centralizada. ¿Maquiladoras de cuarta generación en Mexico? Estudios Sociológicos, 22(66), 647-667.

Cimoli, M., Correa, N., \& Primi, A. (2003). Crecimiento y estructura productiva en economías abiertas: Lecciones de la experiencia de América Latina. Santiago de Chile: Comision Economica para America Latina y El Caribe.

Comisión Económica para América Latina y El Caribe. (2007). Progreso técnico y cambio estructural en América Latina. 
Driffield, N. L., \& Kambhampati, U. S. (2003). Trade Liberalization and the Efficiency of Firms in Indian Manufacturing. Review of Development Economics, 7(3), 419-430. doi: 10.1111/14679361.00200

Euromonitor International. (2012). Base de datos de la Herramienta Passport. Recuperado de http: //www.euromonitor.com/passport-gmid

Furtado, C. (1961). Desarrollo y subdesarrollo. México: Fondo de Cultura Económica.

Goldar, B., \& Kumari, A. (2003). Import Liberalization and Productivity Growth in Indian Manufacturing Industries in the 1990s. The Developing Economies, 41(4), 436-60. doi: $10.1111 / \mathrm{j} .1746$ 1049.2003.tb01010.x

Government of India. Department of Scientific and Industrial Research. (1992). Annual Register of Foreign Collaborations, 1980-1992. Delhi: Autor.

Greenwald, B., \& Kahn, J. (2005). All strategy is local. Harvard Business Review, 95-104.

Guillén, H. (2013). México: De la sustitución de importaciones al nuevo modelo económico. Comercio Exterior, 63(4), 33-60.

Guzmán, a., \& Zúñiga, M. (2004). Patentes en la industria farmacéutica de México: Los efectos en la investigación, el desarrollo y en la innovación. Comercio Exterior, 12(54), 1104-1121.

Hanson, G. (2010). Why isn't Mexico Rich (N. ${ }^{\circ}$ Working Paper Núm. 16470). Cambridge: National Bureau of Economic Research.

Hashim, D., \& Virmani, A. (2011). J-Curve of productivity and growth: Indian manufacturing postliberalization. Washington, DC.: International Monetary Fund.

Hellman, D. (1976). Shift Share models as predictive tools. Growth and change, 7(3), 3-8.

Hernández, E. (2000). La competitividad industrial en México. México: Plaza y Valdés/Universidad Autónoma de México.

Holland, M., \& Porcile, G. (2005). Brecha tecnológica y crecimiento en América latina. En M. Cimoli (Ed.), Heterogeneidad estructural, asimetrías tecnológicas y crecimiento en América Latina (pp. 40-71). Santiago de Chile: Comision Economica para America Latina y El Caribe/Banco Internacional del Desarrollo.

Kim, S., \& Saravanakumar, M. (2012). Economic Reform and Total Factor Productivity Growth in Indian Manufacturing Industries: Reform and productivity in India. Review of Development Economics, 16(1), 152-166. doi: $10.1111 / \mathrm{j} .1467-9361.2011 .00652 . \mathrm{x}$

Kuczynski, P. P., \& Williamson, J. (Eds.). (2003). After the Washington consensus: Restarting growth and reform in Latin America. Washington, DC: Institute for International Economics.

Lin, J. Y. (2015). The Washington Consensus revisited: A new structural economics perspective. Journal of Economic Policy Reform, 18(2), 96-113. doi: 10.1080/17487870.2014.936439

Martínez, R., \& Soto, E. (2012). Consenso de Washington: La instauración de las políticas neoliberales en América Latina. Política y Cultura, 96-113.

McMillan, M., \& Rodrik, D. (2014). Globalization, Structural Change, and Productivity Growth, with an Update on Africa. World Development, (63), 11-32.

McMillan, M., \& Rodrik, D. (2017). Structural Change, Fundamentals and Growth: A Framework and Case Studies (N. ${ }^{\circ}$ Working Paper Núm. 23378). Cambridge: National Bureau of Economic Research.

Ministry of Statistics and Programme Implementation. (2012). Annual Survey of Industries (ASI). National Sample Survey Office: Industrial Statistics Wing. Recuperado de http://www.csoisw.gov. in/ 
Pattnayak, S., \& Thangavelu, S. (2001). Economic Liberalization and Productivity Growth: A Disaggregated Analysis of Indian Manufacturing Industries. Presentado en Australia. Recuperado de http://www.econometricsociety.org/meetings/am01/content/presented/papers/pattnayak. pdf

Peres, W. (2006). El lento retorno de las políticas industriales en América Latina y el Caribe. Revista CEPAL, (88), 71-88.

Pinto, A. (1965). Concentración del progreso técnico y de sus frutos en el desarrollo de América Latina. El Trimestre Económico, 32, 3-69.

Prebisch, R. (1950). The economic development of Latin America and its principal problems. Nueva York: Naciones Unidas, CEPAL.

Puyana, A., \& Romero, J. (2006). Hacia una evaluación de los efectos multiplicadores de la actividad maquiladora. Estudios Sociológicos, 24(70), 65-97.

Roncolato, L., \& Kucera, D. (2014). Structural drivers of productivity and employment growth: A decomposition analysis for 81 countries. Cambridge Journal of Economics, 38(2), 399-424. doi: $10.1093 /$ cje/bet044

Srinivasan, T. (1996, septiembre). Indian Economic Reforms: Background, Rationale, Achievements, and Future Prospects. 43. Recuperado de http://citeseerx.ist.psu.edu/viewdoc/download?doi= 10.1.1.39.3892\&rep=rep $1 \&$ type $=$ pdf

Timmer, C. P. (1988). The agricultural transformation. En Handbook of Development Economics (Vol. 1, capítulo 8, pp. 275-331). doi: 10.1016/S1573-4471(88)01011-3

Timmer, M. P., \& De Vries, G. J. (2009). Structural change and growth accelerations in Asia and Latin America: A new sectoral data set. Cliometrica, 3(2), 165-190. doi: 10.1007/s11698008-0029-5

Trivedi, P., Prakash, A., \& Sinate, D. (2000). Productivity in major manufacturing industries in India: 1973-74 to 1997-98 (Development Research Grup Study N. ${ }^{\circ}$ 20). Bombay: Reserve Bak of India.

Uchikawa, S. (2001). Investment Boom and Underutilisation of Capacity in the 1990s. Economic and political Weekly, 36(34), 3247-3254.

Unel, B. (2003). Productivity Trends in India's Manufacturing Sectors in the Last Two Decades. Recuperado de https://www.imf.org/en/Publications/WP/Issues/2016/12/30/Productivity-Trendsin-India-s-Manufacturing-Sectors-in-the-Last-Two-Decades- 16254

United Nations Conference on Trade and Development [UNCTAD]. (2002). World Investment Report 2002: Trasnational Corporations and Export Competitiveness. Nueva York: Naciones Unidas.

United Nations., Economic Commission for Latin America., \& Prebisch, R. (1950). The economic development of Latin America and its principal problems. Lake Success: United Nations Dept. of Economic Affairs.

United Nations Industrial Development Organization. (2012). Indstat 4 (ISIC rev.3) Database. Viena: Autor.

Valenzuela Feijóo, J. (1986). El capitalismo mexicano en los ochenta: Hacia un nuevo modelo de acumulación? México, D.F: Ediciones Era.

Valenzuela, J. (1994). El capitalismo mexicano en los ochenta. México: Ediciones Era.

Vázquez-López, R. (2012). Heterogeneidad y cambio estructural en el sector manufacturero mexicano. En M. González \& B. Olmedo (Eds.), Globalización y dinamismo manufacturero: México y otros países emergentes (pp. 19-44). México: Universidad Nacional Autónoma de México. 
Vázquez-López, R. (2013). Heterogeneidad estructural y sus determinantes en la manufactura mexicana, 1994-2008. Revista CEPAL, (109), 125-141.

Villarreal, R., \& Ramos, R. (2001). La apertura de México y la paradoja de la competitividad: Hacia un modelo de competitividad sistémica. Comercio Exterior, 51(9), 772-788. 